\title{
Reflexión sobre la enseñanza \\ de la historia de la arquitectura
}

Pondering over the teaching
of history of architecture

\author{
Aгq. Patricio Duarte G. + Arq. Isabel Zúñiga L.
}

$<$ Resumen>

El siguiente texto reflexiona en torno a la enseñanza de la Historia de la Arquitectura, exigiendo una mirada cuidadosa de los estilos frente a las lecturas contemporáneas de los eventos arquitectónicos.

$<$ Abstract $>$

The following text is a reflection on the teaching of the history of architecture. It emphasizes the need to watch architectural styles carefully and to take into account the existence of contemporary interpretations of architectural events.

<Palabras clave>

ENSENANZA DE LA HISTORIA DE ARQUITECTURA / REFORMA DEL PREGRADO

$<$ Key words>

TEACHI NG OF HI STORY OF ARCHI TECTURE /

UNDERGRADUATE TEACHI NG REFORM

\section{Presentación}

El presente artículo se deriva de la investigación "Una Propuesta Docente de Transversalidad para la Carrera de Arquitectura" en la cual se pretende el diseño de una experiencia docente que integre las Cátedras de Historia de la Arquitectura y de Estructuras. Dicha investigación fue formulada, inicialmente, en el marco del Proyecto MECESUP UCH-0217 que promovía el avance en el desarrollo de propuestas pedagógicas en pos de transformar los procesos formativos hacia visiones más integradoras, transversales y colaborativas. Posteriormente el planteamiento investigativo continuó su desarrollo como Proyecto de Investigación FAU 2005. De los alcances contenidos en dicha investigación a continuación se expone las consideraciones críticas respecto de la enseñanza de la Historia de la Arquitectura.

Considerando que una de las deficiencias que presenta la enseñanza universitaria en general -y de la arquitectura en nuestro caso particular- es la marcada especificidad e independencia disciplinar con que muchas veces se tratan las materias que conforman los programas curriculares, se plantea una revisión del enfoque con que habitualmente se estudia la Historia de la Arquitectura. Se postula que dicho giro metodológico posibilitaría una comprensión e interpretación transversal del hecho arquitectónico, alentando enlaces transdisciplinares, acorde a las innovaciones docentes que la enseñanza universitaria exige en la actualidad.

Historia de la Arquitectura. Docencia transversal

\section{Exposi ción}

Tal como lo señala Joaquín Arnau: "La Arquitectura es, como todo acontecimiento humano, objeto de la Historia. Pero es, además y en primer lugar, sujeto de esa misma Historia. La Arquitectura hace Historia" (Arnau 2000). En la radicalidad de esta sentencia es quizás donde se explica el porqué la revisión de lo que ha sido el quehacer disciplinar que antecede a la realidad arquitectónica presente constituye una de las líneas de conocimiento que se considera útil dentro de la formación 
académica de los alumnos de arquitectura en nuestra Facultad. De hecho, tradicionalmente, la Historia de la Arquitectura ha formado parte de los programas docentes en los centros de enseñanza de la arquitectura, y con mayor razón de aquellos fundados bajo el modelo del academicismo decimonónico -como es el caso particular de nuestra escuela- en el cual el conocimiento de la arquitectura del pasado era considerado indispensable para dar forma a la creación arquitectónica.

Desde ese ya lejano origen, dicho campo del conocimiento, salvo breves excepciones, ha formando parte del currículo formativo de nuestros estudiantes aunque, evidentemente, ha ido variando en el tiempo el enfoque y el énfasis que este saber ha ido asumiendo dentro de la enseñanza de la arquitectura.

En la actualidad, retomando las ideas iniciales de Joaquín Arnau, podríamos entender que un curso de Historia de la Arquitectura cumple el objetivo de que los alumnos asimilen cómo se ha ido configurando en el tiempo la acción arquitectónica a modo de un discurso disciplinar continuo y en evolución y comprender y valorar la existencia de obras que generaciones precedentes nos han dejado como legado objetivo; es reconocer la contribución que la arquitectura realiza en la construcción de la historia misma y, por ende, comprender su dimensión trascendente en tanto producto cultural.

Es en ese sentido que el estudio de la arquitectura de épocas pasadas reconoce el significado instrumental y metodológico que le es propio a la disciplina histórica: es el medio que permite transmitir la memoria de una sociedad o cultura, promover su adecuada comprensión y análisis y perseguir su explicación. Pareciera ser que, de acuerdo a esto último, la Historia de la Arquitectura manifiesta desde ya una connotación transversal y transdisciplinar, ya que da la posibilidad de interpretar la creación arquitectónica inserta en un marco de discusión mayor dadas las repercusiones y relaciones que ésta establece al interior de la sociedad; ello es lo que permite ampliar la mirada y plantear asociaciones diversas.

Es precisamente el enfoque desde una visión de lo cultural y/o social una posibilidad cierta de cómo poder enfrentar el reconocimiento histórico de la Arquitectura; de hecho así ha sido abordada o ha sido necesario abordarla, sobre todo si se tiene en cuenta la conciencia que sobre su valor patrimonial, y por tanto constructora de identidad, se ha ido gestando de un tiempo a esta parte a nivel de la discusión ciudadana.
Al respecto cabe señalar que justamente es el cambio de los enfoques interpretativos lo que ha caracterizado la evolución de la disciplina historiográfica en general; cambio que en buena medida obedece a la confrontación natural que se va produciendo entre el avance de las ideas al interior de la sociedad y los supuestos sobre los que se basan los enfoques historiográficos que comienzan a quedar obsoletos respecto de la utilidad que dicha sociedad demanda de la disciplina histórica: es lo que obliga a una continua actualización y renovación de la forma de mirar y construir el pasado en la perspectiva de comprender, a su vez, el presente.

"A comienzos del siglo xx empezaba a resultar visible el agotamiento de los viejos métodos de erudición histórica académica del siglo XIX, con sus pretensiones de objetividad científica, que enmascaraban el hecho de que su función real era la de servir, por un lado, para la educación de las clases dominantes y, por otro, para la producción de una visión de la historia nacional que se pudiera difundir al conjunto de la población a través de la escuela" (Fontana; 2002: 9).

Lo anterior demuestra que la Historia no constituye una disciplina de carácter estático, que establece un saber inamovible, como pudiese pensarse habitualmente, sino que está alentada por el espíritu que cada época y cada historiador le imprime y que posibilita su constante construcción. Sin embargo, a pesar de esta situación, existe algo esencial que es lo que le da el sentido a la disciplina histórica y que está por sobre cualquier relativismo circunstancial, y que tiene que ver con su voluntad de comprender el pasado. El profesor de la Historia del Arte y de la Arquitectura Antonio Pizza, establece, al respecto, una definición de la función del historiador que, extrapolándola, bien sirve, a su vez, para reafirmar la función académica de la Historia en general, y de la Arquitectura en particular; dicho autor señala:

"El historiador, en definitiva, asume dos funciones prioritarias: la de construir un saber que emana de sus empresas cognoscitivas y la de contribuir a consolidar una memoria colectiva; aspectos que, en términos seguramente reductivos, podríamos encontra reflejados en la vida académica, en sus dos facetas de investigación y docencia.

Sea cual sea la articulación del saber histórico, no obstante, nos parece prioritario determinar el carácter crítico de sus planteamientos; se trata, en resumidas cuentas, de generar y transmitir un conocimiento transmutado en memoria, cuyo principal requisito será el de configurar sus resultados no como soluciones, salvaciones o catarsis, sino -fundamentalmente- como problemas. La consideración del pasado en sus aspectos problemáticos irá demostrando su productividad respecto al ejercicio de una actitud crítica frente a nuestra contemporaneidad; por tanto, sólo si somos capaces de construir un pasado, podremos estar en condiciones de proyectar nuestro futuro, a partir de la ineludible valorización de la libertad creativa de nuestro pensamiento" (Pizza; 2000: 10-11).

En el caso específico de la Historia de la Arquitectura, la memoria a que hace alusión este autor está constituida por obras -edificios- que constituyen aquellos acontecimientos o sucesos que van señalando el paso del tiempo como manifestación de la acción social, las concepciones estéticodisciplinares y el afán constructivo del hombre son algunas de las acepciones críticas que la dimensión histórica del hecho arquitectónico sugiere y que han dado pie a similar número de enfoques analíticos.

Por otra parte, producto de la necesidad de interpretar y ordenar dicha producción edificada, la historiografía arquitectónica hace uso del concepto de período -propio a la disciplina histórica de por sí- en base al cual estructura la comprensión del proceso histórico como una sucesión de etapas que responden a la caracterización de distintos códigos histórico-estéticos (estilos).

Habría que señalar, eso sí, que esta periodización tradicionalmente ha dado cuenta de esquemas interpretativos derivados de la Historia del Arte, delatando con ello una interrelación que habla de un corpus historiográfico común respecto de las llamadas tres grandes artes (escultura, pintura y arquitectura), el cual caracterizó el inicio de la Historia de la Arquitectura (no debe olvidarse al respecto, que hasta el siglo xIx Arte y Arquitectura presentaron una forma de visión compartida y en muchas ocasiones los campos de acción respectivos tendían a conjugarse). 
Sin entrar en mayores detalles, es esta visión cronológica secuencial, de carácter positivista, la que ha permanecido vigente en el tiempo y la que ha inspirado o condicionado tradicionalmente la historiografía arquitectónica, sobre todo en el ámbito de la enseñanza. Puede que en ello influya el hecho que este método establece una forma de comprender la realidad histórica que no permite, en principio, mayores cuestionamientos al representar una aproximación que, a través de la generalización, suministra una comprensión ordenada y racional de lo que ha sido el desarrollo de la arquitectura en el tiempo en cuanto expresión artística; constituye un resguardo clasificatorio que a juicio de algunos autores actuales, sin embargo, remite el análisis historiográfico a una mera faena de índole arqueologizante.

Igualmente, habría que señalar que este método es aplicable al estudio de la Historia de la Arquitectura hasta el momento previo a la irrupción de la Arquitectura Moderna, dado que ésta lo que precisamente pretendía era dejar atrás y anular la idea de estilo, por lo cual la interpretación y análisis centrado en los valores formales da paso a la valoración del espacio como aspecto definitorio y consustancial de la creación arquitectónica; es también el momento en que los caminos del arte y la arquitectura empiezan a individualizarse. Sin embargo, a pesar de ello, la periodización estilística continúa siendo un método de conocimiento histórico vigente hasta la actualidad, aunque el discurso formalista en su momento haya perdido algo de prestigio. Los períodos establecidos mantienen su validez analítica e interpretativa aunque quizás en la actualidad, más que aludir a códigos estilísticos propiamente tales han ampliado su significado -por las razones que ya han sido comentadas- adquiriendo una connotación más bien de índole históricocultural.

Del mismo modo, cabe preguntarse si no es inevitable caer en lo visual o formal al momento de caracterizar una obra de arquitectura, sobre todo si aceptamos que sigue siendo el aspecto que permite reconocer las posibles relaciones que se establecen respecto de otras obras que le son contemporáneas o que le preceden y que configuran de ese modo una producción arquitectónica característica e identificable en un momento particular del decurso histórico.

"La obra de arte no está nunca sola, es siempre una relación. Para comenzar: al menos una relación con otra obra de arte. Una obra sola en el mundo no sería ni siquiera entendida como producción humana, sino mirada con reverencia u horror, como magia, como tabú, como obra de Dios o de un brujo, no del hombre. Y hemos padecido ya mucho del mito de los artistas divinos, y divinísimos, en lugar de simplemente humanos. Es, pues, el sentido de apertura que da necesidad a la respuesta crítica. Respuesta que no implica solamente el nexo entre obra y obras, sino entre obra y mundo, sociedad, economía, religión, política y todo cuanto ocurra" (Longh en Pizza; 2000: 132).

Así se habla en la actualidad, por ejemplo, de arquitectura decontructivista, término que no en menor medida se comprende desde la visualidad en que esa manifestación del pensamiento arquitectónico contemporáneo se ha ido representando. La diferencia, quizás, es que ahora no se reconoce un código formal establecido, a modo de un estilo, sino más bien corresponde hablar de tendencias que establecen principios abstractos que guían y estimulan la expresión arquitectónica. Incluso más, se da el hecho que puedan coexistir diversas tendencias en un mismo momento histórico.

En todo caso es quizás desde lo visual donde mejor se explicita el cambio o transformación y la innovación arquitectónica, definiendo líneas de producción arquitectónica temporales características, y es por ello por lo cual resulta un aspecto del cual es difícil prescindir para interpretar y reconocer el desarrollo histórico de la arquitectura; es el modo cómo se devela la estrecha relación entre realidad histórica y el hecho arquitectónico como manifestación y expresión de esa realidad; es la constatación inmediata de esa condición de objeto y sujeto histórico que ostenta la arquitectura según lo señalado en la cita de Joaquín Arnau con que iniciábamos este apartado.

Sin embargo, habría que señalar que este procedimiento historiográfico podría presentar algunos inconvenientes respecto de la percepción que sobre el desarrollo histórico arquitectónico pudiese formarse en último término.

A nuestro juicio la periodización, estableciendo una secuencia de etapas desde lo figurativo, tiende a promover una visión que favorece más bien una noción de discontinuidad que resulta negativa desde la perspectiva de un enfoque docente de carácter transversal, ya que no fomenta una comprensión integral y trascendente de la disciplina arquitectónica.

Esta apreciación encuentra sentido si se considera que muchas de las veces dicha secuencia se va explicando producto de un proceso de algún modo dialéctico, donde la generación de un nuevo período surge en oposición al que le precede desdibujando así la continuidad que pudiese existir entre uno y otro, en cuanto transmisión de ciertos legados disciplinares. Los ejemplos sobran al respecto, siendo más comunes en las etapas o períodos que se establecen a partir de la llustración en adelante; así el Neoclásico se entiende como una restitución racionalista de la forma arquitectónica respecto del desenfreno formal del Barroco, o más cercano a nuestra realidad presente, la radicalidad del surgimiento de la Modernidad que reniega de todo precedente histórico, o últimamente, la Posmodernidad que, de forma menos extrema, igualmente se funda como una crítica respecto de los ideales que ésta planteaba. 
Es por ello que mediante esta visión histórica se subentiende el principio de cambio como un valor superior, connatural al desarrollo de la arquitectura en el tiempo, en que el pasado inmediato sólo interviene como detonante del cambio; cambio que se hace reconocible de forma más elocuente e identificable desde la manifestación aparente de la arquitectura y que en buena medida condiciona dicha visión histórica.

Esta manera de ver el desarrollo histórico de la arquitectura es claro que se entiende deudora del espíritu de progreso continuo propiciado por la modernidad y que en la actualidad ha adquirido una dinámica aún más avasalladora; es lo que sería responsable de ese espíritu innovador constante desde lo formal con rasgos cada vez más individualistas y que, por lo mismo, tiende a establecer una actitud centrada en relatar y entender los acontecimientos desde su propia circunstancia e individualidad disciplinar, lo cual, en último término, atenta en buena medida respecto de lo que pudiese ser una visión histórica transversal de la arquitectura.

Vistos así los hechos cabe preguntarse si no sería posible intentar una revisión histórica diferente, que permita ir más allá de lo visual y del cambio continuo para entender como se ha ido desenvolviendo la arquitectura en el tiempo, reconociendo aquellos aspectos que puedan exhibir una condición perdurable más allá de las variaciones de apariencia más evidentes, y por lo mismo, hacer manifiestos algunos principios de continuidad disciplinar que a primera vista pudiesen estar algo ocultos.

Al respecto se postula que ello podría alcanzarse mediante un enfoque distinto que fuese dando cuenta de aquellos procesos de más larga duración y que obedecen a factores que delatarían una connotación que dan cuenta de la condición plural del hecho arquitectónico. Es intentar una aproximación retrospectiva del hecho arquitectónico reconociendo determinantes que inciden en ella desde ámbitos extraartísticos y por lo mismo insinuando relaciones transdisciplinares que evidencien el carácter transversal que alienta la creación arquitectónica, lo cual asumiría un valor ejemplar desde el punto de vista docente.

Frente al requerimiento de instituir una noción diferente de revisar la historia de la arquitectura debemos señalar que ello no representa necesariamente una propuesta original, pues ya varios historiadores de la arquitectura han avanzado en este sentido.
Fernando Chueca Goitia con su Método de las Invariantes -publicado en 1947- realizó, sin duda, una aproximación germinal en ese sentido; dicho autor, desde una aproximación sociológica, haciendo uso del concepto de intrahistoria, destaca precisamente aquellas concepciones arquitectónicas que se mantienen inmutables en el tiempo -invariantes- al interior de una sociedad determinada y que en último término forman parte de su identidad (Chueca Goitia, 1979).

Por otra parte, más reciente y cercana a nuestra realidad local, la teórica e historiadora de la arquitectura Marina Waisman, cuestionó la aplicabilidad de la periodificación convencionalmente establecida para la Historia de la Arquitectura en el contexto latinoamericano, donde los criterios estilísticos no alcanzan suficiente coherencia interpretativa destacando, por contrapartida, las circunstancias anestéticas como aspectos determinantes para comprender y valorar la producción arquitectónica continental; de ahí que esta autora plantee lo relativo de las periodificaciones universalistas y sugiera la necesidad de establecer nuevos criterios en ese sentido, adecuados a la complejidad y diversidad de la realidad histórica.

"De esta experiencia puede inferirse que las pautas para establecer una periodificación no solamente pueden diferir de una cultura a otra, sino que pueden asimismo ser diferentes para distintos períodos de la historia de un país. Cuando intervienen nuevos elementos, que no existían en el pasado, puede resultar indispensable incorporarlos para la definición de una unidad histórica. Para el caso de América Latina, en general, pienso que las pautas extra-arquitectónicas, aquellas referidas al contexto social en todos sus aspectos, desempeñan un papel preponderante para la periodificación a lo largo del período colonial y del siglo xIx; en tanto al comenzar el siglo xx, deberán incorporarse los aspectos ideológicos específicos de la arquitectura, las corrientes arquitectónicas tanto propias como universales". (Waisman, 1993; p. 50)

Es importante señalar que estas reflexiones conducirán a la autora a señalar la utilidad que podría desempeñar para reenfocar la historiografía arquitectónica la aplicación de concepto de las duraciones históricas propio al pensamiento del historiador francés Fernand Braudel

Para este importante representante de la escuela historiográfica francesa contemporánea, iniciada en la segunda década del siglo xx por Lucien Febvre y Marc
Bloch, el estudio del pasado puede enfrentarse desde diferentes miradas dependiendo de la trascendencia temporal de los fenómenos históricos que se analicen.

Así habría que distinguir lo que constituyen los acontecimientos, que refieren a los sucesos de corta duración, de índole cotidiana, que constituyen la aprehensión más inmediata de la realidad histórica y cuya conciencia resulta más evidente pero a la vez, la mayor parte de las veces, más pasajera.

“El pasado está, pues, constituido, en una primera aprehensión, por una masa de hechos menudos, los unos resplandecientes, los otros oscuros e indefinidamente repetidos; precisamente aquellos hechos con los que la microsociología o la sociometría forman en la actualidad su botín cotidiano (también existe una microhistoria). Pero esta masa no constituye toda la realidad, todo el espesor de la historia, sobre el que la reflexión científica puede trabajar a sus anchas. La ciencia social casi tiene horror del acontecimiento. No sin razón: el tiempo corto es la más caprichosa, la más engañosa de las duraciones". (Braudel, 1980; p. 66)

El relato histórico de corta duración es episódico, apegado al discurso rigurosamente cronológico que persigue reconstituir con exactitud la secuencia de los hechos, tal como tradicionalmente se ha entendido la historia política.

Sin embargo, Braudel plantea la necesidad de superar dicho relato convencional con el objeto de revelar la historia de hechos que dan cuenta de un tiempo diferente al tiempo histórico tradicional. Es el caso de la historia económica que debe dar cuenta de un desenvolvimiento de fenómenos en el tiempo que hace necesario enfrentar su relato de forma algo distinta.

"Un día, un año, podían parecerle a un historiador político de ayer medidas correctas. 
El tiempo no era sino una suma de días. Pero una curva de precios, una progresión demográfica, el movimiento de salarios, las variaciones de la tasa de interés, el estudio (más soñado que realizado) de la producción o un análisis riguroso de la circulación exigen medidas mucho más amplias.

Aparece un nuevo modo de relato histórico -cabe decir el "recitativo" de la coyuntura, del ciclo y hasta del "interciclo"- que ofrece a nuestra elección una decena de años, un cuarto de siglo y, en una última instancia, el medio siglo del ciclo clásico de Kondratieff". (Braudel, 1980; p. 68).

La constatación de estas coyunturas, definiendo períodos cronológicos, le permiten a Braudel establecer la noción histórica de la media duración y suponer, a la vez, la existencia de procesos que den forma a un relato histórico de aún mayor amplitud temporal; es el relato de la larga duración en donde el objeto de estudio se centra en el reconocimiento de las estructuras que de forma menos elocuente conducen en buena medida el devenir histórico.

"Los observadores de lo social entienden por estructura una organización, una coherencia, unas relaciones suficientemente fijas entre realidades y masas sociales. Para nosotros los historiadores, una estructura es indudablemente un ensamblaje, una arquitectura; pero más aún, una realidad que el tiempo tarda enormemente en desgastar y en transportar. Ciertas estructuras están dotadas de tan larga vida que se convierten en elementos estables de una infinidad de generaciones: obstruyen la historia, la entorpecen y, por tanto, determinan su transcurrir. Otras por el contrario, se desintegran más rápidamente. Pero todas ellas, constituyen, al mismo tiempo, sostenes y obstáculos. En tanto que obstáculos, se presentan como limitaciones (envolventes, en el sentido matemático) de los que el hombre y sus experiencias no pueden emanciparse. Piénsese en la dificultad de romper ciertos marcos geográficos, ciertas realidades biológicas, ciertos límites de productividad, y hasta determinadas coacciones espirituales: también los encuadramientos mentales representan prisiones de larga duración". (Braudel, 1980; pp. 70-71).

Estas ideas planteadas por Braudel en el año 1958 siguen siendo aún sumamente sugerentes; de hecho, como ya señalábamos, Marina Waisman las recogió en su momento proponiendo su aplicación al estudio histórico de la arquitectura latinoamericana. Así esbozó un paralelo entre las categorías definidas por el historiador francés y la producción arquitectónica local. El relato de corta duración encontraría su correlato en el estudio de obras y proyectos; la media duración correspondería a la producción de un arquitecto o incluso en algunos casos el desarrollo de un estilo o una fase de éste; finalmente, la autora argentina asimila la larga duración a la historia urbana, los códigos lingüísticos, ciertas "invariantes" nacionales o regionales o a ciertos tipos arquitectónicos (Waisman, 1993; p. 56)

Creemos que el tema no está agotado en la aproximación realizada por Marina Waisman, sino, por el contrario, la posibilidad, o desafío, de aplicar el pensamiento de Braudel a la Historia de la Arquitectura permanece aún vigente, sobre todo porque su noción de la larga duración podría concordar, en buena medida, con un posible enfoque desde la condición transversal que es propia al hecho arquitectónico.
Es posible sostener, sin demostrar gran originalidad, que en su desarrollo histórico, la arquitectura ha estado determinada por factores "estructurales" que escapan de su propia contingencia disciplinar y que por lo mismo merecen un enfoque o relato histórico diferente al habitual recuento del cambio figurativo. A diferencia de Braudel, eso si, no entenderíamos que estos factores han actuado como impedimentos, sino que son parte de un proceso de más lenta evolución relacionado con la dimensión material del hecho arquitectónico y que, como se ha señalado, están condicionados por el aporte de otros campos disciplinares o procesos que repercuten en la disciplina arquitectónica. No deja de ser provocador, en todo caso, interpretar el desarrollo histórico de la arquitectura como la constante lucha del proyecto por superar los límites que imponen restricciones de diversa índole y que, a su vez, es la tensión que promueve el progreso disciplinar.

\section{Bibliografía}

Arnau, J. 72 voces para un diccionario de arquitectura teórica. Madrid: Celeste Ediciones, 2000.

Braudel, F. La Historia y las Ciencias Sociales. Alianza Editorial, Madrid, 1980

Chueca Goitia, F. Invariantes castizos de la arquitectura española. Madrid: Editoria Dossat, 1979.

Fontana, J. La historia de los hombres: El siglo XX. Barcelona: Editorial Crítica, 2002.

Pizza, A. La construcción del pasado. Madrid: Celeste Ediciones, 2000

Waisman, M. El interior de la historia: Historiografía arquitectónica para uso de latinoamericanos. Bogotá: Escala, 1993. 